\title{
Assessment of Hand Hygiene Knowledge among Residents and Nursing staffs at Nobel Medical College Teaching Hospital, Biratnagar
}

\author{
Yadav SK ${ }^{1}$, Giri A ${ }^{2}$
}

\section{Abstract}

Introduction: Hand hygiene is a very simple and cost effective procedure to prevent cross-transmission of microorganisms. The compliance of residents and nursing staffs with hand hygiene guidelines seems to be vital in preventing disease transmission among patients. The objective of the study was to assess the knowledge of residents and nursing staffs with regard to hand hygiene. Material and Methods: This was an institution based descriptive cross-sectional study conducted among 55 respondents (29 nursing staffs and 26 resident doctors) of department of paediatrics, Nobel Medical College in Biratnagar, Nepal. Knowledge was assessed using WHO hand hygiene questionnaire for health care workers. Chi square test was used to compare the percentage of correct responses between resident doctors and nursing staffs. Apvalue of $<0.05$ was considered significant. Results: Among 26 resident doctors and 29 nursing staffs who participated in the study, $30.7 \%$ of resident doctors and $55.1 \%$ of nursing staffs had received formal training in hand hygiene in the last three years. Only $9 \%$ of participants (5 out of 55 ) had good knowledge regarding hand hygiene. Conclusions: The knowledge regarding hand hygiene is limited among the study population. The study recommends the need for emphasizing hand hygiene component in the preservice as well as inservice training programs of doctors and nurses.

Key words: Hand hygiene, knowledge, resident, nursing staff.

\section{Introduction}

$\mathrm{H}^{2}$ and hygiene is a general term that applies to either hand washing, antiseptic hand wash, antiseptic hand rub, or surgical hand antisepsis ${ }^{1}$. Hand hygiene is a simple measure to prevent crosstransmission of microorganisms and to reduce the incidence of health care associated infections ${ }^{2,3}$. Health Care Professionals (HCPs) hands become progressively colonized with commensal flora as well as with potential pathogens during patient care ${ }^{4}$. Hand hygiene is one of the five key initiatives set out by the World Alliance for Global Patient Safety Challenges ${ }^{5}$.

Despite the relative simplicity of this procedure, compliance with hand hygiene among HCPs is as low as $40 \% \%^{2,6,7}$. To address
${ }^{1}$ Dr. Sunil Kumar Yadav, MBBS, MD, DM. ${ }^{2} \mathrm{Dr}$. Arun Giri, MBBS. MD. Both from the Department of Paediatrics and Neonatology, Nobel Medical College Teaching Hospital, Biratnagar, Nepal.

\author{
Address for correspondence \\ Dr. Sunil Kumar Yadav \\ MBBS, MD, DM Neonatology \\ Department of Pediatrics and Neonatology \\ Nobel Medical College Teaching Hospital \\ (NMCTH), Biratnagar \\ Tel No: +9779817930222 \\ E-mail: dr.sunil_yadav@yahoo.com
}

Acknowledgements: We are grateful to all nurses and junior doctors who are dedicated for the care of newborn.

Funding: Nil

Conflict of Interest: None

Permission from IRB: Yes

\section{How to cite}

Yadav SK, Giri A. Assessment of Hand Hygiene Knowledge among Residents and Nursing staffs at Nobel Medical College Teaching Hospital, Biratnagar. J Nepal Paediatr Soc 2018;38(2):69-73.

doi: http://dx.doi.org/10.3126/jnps.v38i2.20547

This work is licensed under a Creative Commons Attribution 3.0 License.

\section{(c) (i)}


this problem, continuous efforts are being made to identify effective and sustainable strategies. One ofsuch efforts is the introduction of an evidence-based concept of "My five moments for hand hygiene" by World Health Organization. These five moments that call for the use of hand hygiene include the moment before touching a patient, before performing aseptic and clean procedures, after being at risk of exposure to body fluids, after touching a patient, and after touching patient's surroundings. This concept has been aptly used to improve understanding, training, monitoring, and reporting hand hygiene among $\mathrm{HCPs}^{2}$.

Nurses and resident doctors constitute the largest percentage of the HCPs. Because they spend more time with patients than any other HCPs, their compliance with hand washing guidelines seems to be vital in preventing the disease transmission among patients.

In Asian countries like Nepal, there is a paucity of studies exploring this subject, although the prevalence of health care associated infections is high in this region; especially medical and nursing staffs' knowledge of standard precautions is rarely studied ${ }^{8,9,10}$. The observation of hand hygiene by residents has been reported to be weak ${ }^{11,12}$. Therefore, it is essential to investigate health professionals' knowledge regarding hand washing so that appropriate strategies can be developed to promote hand washing compliance ${ }^{13,14}$. The objective of the study was to assess the knowledge of residents and nursing staffs with regard to hand hygiene.

\section{Materials and Methods}

This cross-sectional study was conducted in Department of Paediatrics, Nobel Medical College Teaching Hospital (NMCTH), one of the biggest teaching hospitals in eastern part of Nepal. The hospital currently had 911 beds of its own at full function. It serves the patients from various communities of Nepal and adjoining Bihar state of India. The study was conducted in a period of one month from May to June 2018. Ethical clearance was obtained from the Ethical Review Committee of Nobel Medical College. Resident doctors and nursing staffs were explained the content and nature of the study. Verbal consent was obtained from 26 resident doctors and 29 nursing staffs who volunteered to participate. Knowledge was assessed using $\mathrm{WHO}$ hand hygiene questionnaire for health care workers. This questionnaire included 25 dichotomous "yes" or "no" questions; and "true" or "false" questions. One mark was given for each correct response so that maximum score for knowledge was 25 . A score of more than $75 \%$ was considered good, $50-74 \%$ moderate, and less than $50 \%$ was taken as poor. Data was analysed using SPSS 16 version software. Descriptive statistics was used to calculate percentages for each of the responses given. Chi square test was used to compare the percentage of correct responses between resident doctors and nursing staffs. A $p$-value less than 0.05 was considered significant.

\section{Results}

A total of 55 participants were enrolled in the study. Among the respondent 26 (47.3\%) were resident doctors and $29(52.7 \%)$ were nursing staffs. Their demographic profiles are depicted in Table 1. Within resident doctors, $76.9 \%$ were male and all nursing staffs were female.

Less than one-thirds $(30.7 \%)$ of resident doctors and majority $(55.1 \%)$ of nursing staffs had received inservice training in hand hygiene in the last three years.

Knowledge regarding different aspects of hand hygiene among the respondents is presented in Table 2 that reveals $92.3 \%$ of residents and $86.2 \%$ of nursing staffs answered correctly for the main route of cross transmission of harmful germs between patients in health care facility. About two-fifth (42.3\%) of residents and about one-thirds (31.0\%) of nursing staffs knew about the most frequent source of germs responsible for health care associated infections. Regarding hand hygiene activities preventing transmission of germs to the patient, residents and nursing staffs had similar awareness with respect to practice like immediately after a risk of body fluid exposure, before touching a patient, after exposure to the immediate surroundings of a patient and immediately before a clean/aseptic procedure. Regarding hand hygiene actions preventing transmission of germs to health care worker, higher awareness was seen among nursing staffs with respect to practice like immediately after a risk of body fluid exposure but the difference was not statistically significant. Nursing staffs had more knowledge on hand hygiene practices like after exposure to the immediate surroundings of a patient $(82.8 \%)$ and immediately before a clean/aseptic procedure $(27.6 \%)$.

Table 2 also reveals knowledge on hand rub and hand washing with soap and water. Eighty eight percent of resident doctors correctly stated that hand rubbing is more rapid for hand cleansing whereas, $62.1 \%$ of nursing staffs correctly stated about hand rubbing causing skin dryness more than hand washing. Eighty five percent of resident doctors agreed that hand rubbing is not more effective than hand washing. Most $(80.8 \%)$ of resident doctors were correct about hand washing and hand rubbing not being done in sequence. Majority (65.4\%) of residents and $20.7 \%$ of nursing staffs had answered 
Table 1: Sex and In-service Training Distribution of the Respondents

\begin{tabular}{|c|c|c|c|c|}
\hline \multirow{2}{*}{ Characteristics } & \multicolumn{2}{|c|}{ Resident doctors $(n=26)$} & \multicolumn{2}{|c|}{ Nurses $(n=29)$} \\
\hline & Number & Percent (\%) & Number & Percent (\%) \\
\hline \multicolumn{5}{|l|}{ Sex } \\
\hline Male & 20 & 76.9 & 0 & \\
\hline Female & 6 & 23.1 & 29 & 100.0 \\
\hline \multicolumn{5}{|c|}{ In-service training received on hand hygiene within past three years } \\
\hline Yes & 8 & 30.8 & 16 & 55.2 \\
\hline No & 18 & 69.2 & 13 & 44.8 \\
\hline
\end{tabular}

Table 2: Knowledge of the Respondents regarding Different Aspects of Hand Hygiene $(n=55)$

\begin{tabular}{|c|c|c|c|}
\hline Items & $\begin{array}{l}\text { Resident doctors } \\
(n=26) f(\%)\end{array}$ & $\begin{array}{l}\text { Nurses }(n=29) \\
\text { f (\%) }\end{array}$ & $p$-value \\
\hline $\begin{array}{l}\text { Main route of cross-transmission of potentially harmful germs } \\
\text { between patients in a health-care facility as (health care workers } \\
\text { uncleaned hands) }\end{array}$ & $24(92.3)$ & $25(86.2)$ & 0.362 \\
\hline $\begin{array}{l}\text { Most frequent source of germs responsible for health care- } \\
\text { associated infections as (germs already present on or within the } \\
\text { patient) }\end{array}$ & $11(42.3)$ & $9(31.0)$ & 0.386 \\
\hline \multicolumn{4}{|c|}{ Hand hygiene actions that prevent transmission of germs to the patient as } \\
\hline Before touching a patient (yes) & $20(76.9)$ & $21(72.4)$ & 0.702 \\
\hline Immediately after a risk of body fluid exposure (yes) & $22(84.6)$ & $25(86.2)$ & 0.867 \\
\hline After exposure to the immediate surroundings of a patient (no) & $3(11.5)$ & $9(31.0)$ & 0.081 \\
\hline Immediately before a clean/aseptic procedure (yes) & $21(80.8)$ & $26(89.7)$ & 0.351 \\
\hline \multicolumn{4}{|c|}{ Hand hygiene actions that prevent transmission of germs to the health-care worker as } \\
\hline After touching a patient (yes) & $22(84.6)$ & $26(89.7)$ & 0.576 \\
\hline Immediately after a risk of body fluid exposure (yes) & $19(73.1)$ & $26(89.7)$ & 0.112 \\
\hline Immediately before a clean/aseptic procedure (no) & $6(23.1)$ & $8(27.6)$ & 0.702 \\
\hline After exposure to the immediate surroundings of a patient (yes) & $22(84.6)$ & $24(82.8)$ & 0.853 \\
\hline \multicolumn{4}{|c|}{ Statements on alcohol-based hand rub and hand washing with soap and water that are true are } \\
\hline $\begin{array}{l}\text { Hand rubbing is more rapid for hand cleansing than hand washing } \\
\text { (true) }\end{array}$ & $23(88.5)$ & $16(55.2)$ & 0.007 \\
\hline Hand rubbing causes skin dryness more than hand washing (false) & $15(57.7)$ & $18(62.1)$ & 0.741 \\
\hline $\begin{array}{l}\text { Hand rubbing is more effective against germs than hand washing } \\
\text { (false) }\end{array}$ & $22(84.6)$ & $22(75.9)$ & 0.418 \\
\hline $\begin{array}{l}\text { Hand washing and hand rubbing are recommended to be performed } \\
\text { in sequence (false) }\end{array}$ & $21(80.8)$ & $20(69.0)$ & 0.316 \\
\hline $\begin{array}{l}\text { What is the minimal time needed for alcohol-based hand rub to kill } \\
\text { most germs on your hands? ( } 20 \text { seconds) }\end{array}$ & $17(65.4)$ & $6(20.7)$ & 0.001 \\
\hline \multicolumn{4}{|l|}{ Type of hand hygiene method required: } \\
\hline Before palpation of the abdomen as (rubbing) & $25(96.2)$ & $15(51.7)$ & 0.000 \\
\hline Before giving an injection as (rubbing) & $15(57.7)$ & $16(55.2)$ & 0.851 \\
\hline After emptying a bed pan as (washing) & $23(88.5)$ & $22(75.9)$ & 0.226 \\
\hline After removing examination gloves as (rubbing/washing) & $8(30.8)$ & $15(51.7)$ & 0.116 \\
\hline After making a patient's bed as (rubbing) & $5(19.2)$ & $4(13.8)$ & 0.586 \\
\hline After visible exposure to blood as (washing) & $24(92.3)$ & $22(75.9)$ & 0.100 \\
\hline \multicolumn{4}{|c|}{$\begin{array}{l}\text { Things to be avoided, as they are associated with increased likelihood of colonization of hands with harmful } \\
\text { germs are }\end{array}$} \\
\hline Wearing jewellery (yes) & $25(96.2)$ & $27(93.1)$ & 0.619 \\
\hline Damaged skin (yes) & $20(76.9)$ & $29(100.0)$ & 0.006 \\
\hline Artificial fingernails (yes) & $19(73.1)$ & $28(96.6)$ & 0.014 \\
\hline Regular use of a hand cream (no) & $24(92.3)$ & $17(58.6)$ & 0.004 \\
\hline
\end{tabular}


correctly about the minimal time needed for alcohol based hand rub to kill germs on hand. About $88 \%$ of resident doctors and $76.0 \%$ of nursing staffs knew that hand washing to be done after emptying bed pan. Almost all $(92.0 \%)$ of doctors knew that hand washing should be done after visible exposure to blood. Nursing students were more aware that wearing jewellery $(93.1 \%)$, damaged skin (100\%), and artificial fingernails $(96.6 \%)$ would be associated with increased likelihood of colonization of hands with harmful germs. Almost all $(92.3 \%)$ of resident doctors were aware that regular use of hand cream would not increase the colonization of germs.

The knowledge on most frequent source of germs responsible for health care associated infections and hand hygiene actions preventing transmission of germs to the patient did not differ significantly between residents and nursing staffs, whereas the knowledge on the minimal time needed for alcohol-based hand rub to kill most germs on hands, things to be avoided which has high chance of colonization of germs differed significantly between residents and nursing staffs (Table 2).

\section{Discussion}

Hand hygiene is simple tool in preventing the transmission of nosocomial infections as the hands of health care workers are the most common mode of transmission of pathogens to patients ${ }^{15}$.

In our study, analysis of the responses showed that health care workers had moderate knowledge on hand hygiene, similar to findings of the study conducted in Sri Lanka findings ${ }^{16}$. Though this was a positive finding, major gaps in the knowledge were identified which should be addressed during the future training sessions. Nursing staffs had more knowledge compared to medical students; this may be probably due to hand hygiene related training that they have received. They also spend more time in the wards and have more chance of practicing hand hygiene. Resident doctors knew more about the time and the facts about hand rub and hand washing. They read more about the scientific aspects rather than practicing hand hygiene. They might not be spending more time in the wards which might be the reason for being not aware of hand hygiene aspects during different clinical procedures. For instance they were not aware that hand hygiene is to be practiced before patient contact and after contact with patient surroundings. Another finding in our study was that $65.4 \%$ of the resident doctors and $20.4 \%$ of the nursing staffs knew the minimal time required for alcohol based hand rubs to kill the germs on hands.

In our study $30.7 \%$ of resident doctors and $55.1 \%$ of nursing staffs had formal training on hand hygiene which is very less compared to study done in Raichur by Nair et al in which $74 \%$ medical and $95 \%$ nursing students had formal training ${ }^{17}$. In our study $47 \%$ of resident doctors and only 52\% nursing staffs regularly used alcohol based hand rub compared to $58 \%$ students in a study done in ESIC college Gulbarga by Vinod et al ${ }^{18}$. Most of the doctors and nursing staffs knew the main route of cross transmission of harmful germs in hospitals compared to study done in Sri Lanka by Ariyaratne et. al. in which $73 \%$ of students had answered it correctly. ${ }^{19}$ Less than $50 \%$ of resident doctors in our study knew about most frequent source of germs responsible for health care associated infections compared to $94 \%$ of students in a study done by Arthi et. al. in Puducherry ${ }^{20}$. The knowledge about hand hygiene actions preventing transmission to patients and also to health worker was more among nursing staffs which is comparable to study done in Raichur by Nair et. al. ${ }^{17}$ Sixty five percent of resident doctors knew the minimal time needed for alcohol-based hand rub to kill most germs on hands compared to $15 \%$ in a study done by Arthi et. al. in Puducherry ${ }^{20}$. In our study, resident doctors had good knowledge about hand rubbing, hand washing and its uses in different situations. In contrast nursing staffs were more knowledgeable about the things associated with colonization of hand with harmful germs.

\section{Conclusions}

Knowledge on hand hygiene was moderate among resident doctors and nurses. Inspite of receiving training on hand hygiene, emphasis on hand hygiene in the curriculum of medical students, residents and nurses needs to be given in order to improve student's knowledge about the same.

\section{Limitations}

The results obtained may not truly reflect knowledge of hand hygiene in the population because of the cross sectional study design, institution based study and small sample size. 


\section{References}

1. Larsen EL. APIC Guidelines Committee. APIC Guideline for hand washing and hand antisepsis in health care settings. Am J Infect Control 1995; 23:25169.

2. Pittet $D$, Hougonnet $S$, Harbarth $S$, Mourouga $P$, Souvan V, Touveneau S, et al. Effectiveness of a hospital-wide programme to improve compliance with hand hygiene. Infection Control Programme. Lancet 2000; 356(9238):1307-12.

3. JM Boyce, D Pittet. "Guideline for hand hygiene in health-care settings. Recommendations of the healthcare infection control practices advisory committee and the HICPAC/ SHEA/APIC/IDSA hand hygiene task force," MMWR Recomm Rep 2002; 23(12):S3-S40.

4. WHO Guidelines on Hand Hygiene in Health Care: First Global Patient Safety Challenge Clean Care Is Safer Care. Geneva: World Health Organization; 2009. Available from: https://www.ncbi.nlm.nih.gov/books/ NBK144013/

5. Allegranzia B, Storra J, Dziekana G, Leotsakosb A, Donaldsonb L, Pittet D. The First Global Patient Safety Challenge "Clean Care is Safer Care": from launch to current progress and achievements. Journal of Hospital Inf 2007;65(S2):115-23.

6. Longtin Y, Sax H, Allegranzi B, Schneider F, Pittet D. "Videos in clinical medicine. Hand hygiene." New Eng J Med 2011;364:e24. Available from: http://www.oalib. com/references/14575636

7. Tibballs J. Teaching hospital medical staff to hand wash. Med J Australia 1996;164(7):395-398.

8. Buerhaus PI, Auerbach DI, Staiger DO. Recent trends in the registered nurse labor market in the U.S.: short-run swings on top of long-term trends. Nurs Econ 2007;25(2):59-66.

9. Abualrub RF. Nursing shortage in Jordan: what is the solution? J Prof Nurs 2007;23(2):117-20. DOI: https:// doi.org/10.1016/j.profnurs.2006.07.008

10. Anwar MA, Rabbi S, Masroor M, Majeed F, Andrades M, Baqi S. Self-reported practices of hand hygiene among the trainees of a teaching hospital in a resource limited country. J Pak Med Assoc 2009;59(9):631-34.

11. Patarakul K, Tan-Khum A, Kanha S, Padungpean D, Jaichaiyapum OO. Cross-sectional survey of hand-hygiene compliance and attitudes of health care workers and visitors in the intensive care units at
King Chulalongkorn Memorial Hospital. J Med Assoc Thai 2005;88:S287-293.

12. Kim KM, Kim MA, Chung YS, Kim NC. Knowledge and performance of the universal precautions by nursing and medical students in Korea. Am J Infect Control 2001;29(5):295-300.

13. Awab Ali Ibrahim, Sittana Shamseldin Elshafie. Knowledge, awareness, and attitude regarding infection prevention and control among medical students: a call for educational intervention. Adv Med Educ Pract 2016;7:505-10. DOI: 10.2147/AMEP. $\mathrm{S} 109830$

14. Hunt DC, Mohammudally A, Stone SP, Dacre J. Handhygiene behaviour, attitudes and beliefs in first year clinical medical students. J Hosp Infect 2005;59(4):37173. DOI: 10.1016/j.jhin.2004.09.002

15. Trampuz A, Widmer AF. Hand hygiene: a frequently missed lifesaving opportunity during patient care. Mayo Clin Proc 2004;79(1):109-16. DOI: 10.4065/79.1.109

16. MHJD Ariyaratne, TDCP Gunasekara , MM Weerasekara , J Kottahachchi , BP Kudavidanage, SSN Fernando. Knowledge, attitudes and practices of hand hygiene among final year medical and nursing students at the University of Sri Jayewardenepura. Sri Lankan J Infect Dis 2013;3(1):15-25. DOI: http://dx.doi. org/10.4038/sljid.v3i1.4761

17. Nair SS, Hanumantappa R, Hiremath SG, Siraj MA, Raghunath P. Knowledge, Attitude, and Practice of Hand Hygiene among Medical and Nursing Students at a Tertiary Health Care Centre in Raichur, India. ISRN Prev Med 2014;1:1-4. DOI: 10.1155/2014/608927

18. Vinod S. Kamble, Santosh M. Biradar, Aparna Takpere, Shrinivas Reddy. Knowledge of hand hygiene practices among students of ESIC medical college, Gulbarga, Karnataka, India. Int J Comm Med Pub Health 2016;3(1):94-98. DOI: 10.18203/2394-6040. ijcmph20151234

19. Ansari SK, Gupta P, Jais M, Nangia S, Gogoi S, Satia S, Raza MW. Assessment of the Knowledge, Attitude and Practices Regarding Hand Hygiene amongst the Healthcare Workers in a Tertiary Health Care Centre. International Journal of Pharma Research and Health Sciences 2015; 3(3): 720-726.

20. Arthi E, Abarna V, Bagyalakshmi R, Anitharaj $M$, Vijayasree S. Assessment of Knowledge, Attitude and Practice of Hand Hygiene among Nursing and Medical Students in a Tertiary Care Hospital in Puducherry, India. International Journal of Contemporary Medical Research 2016; 3(4):1203-1206. 